http://jmscr.igmpublication.org/home/

ISSN (e)-2347-176x ISSN (p) 2455-0450

crossref DOI: https://dx.doi.org/10.18535/jmscr/v8i6.61

Journal Of Medical Science And Clinical Research

\title{
Role of antenatal corticosteroids in preterm deliveries
}

\author{
Authors \\ Dr Sapna Berry ${ }^{*}$, Dr Naveen Kumar², Dr Aanya Sharma1, Dr Nancy Thind ${ }^{1}$, \\ Dr Sanjay Rathore ${ }^{1}$ \\ ${ }^{1}$ Department of Obstetrics and Gynecology IGMC Shimla Himachal Pradesh \\ ${ }^{2}$ Department of Pediatrics IGMC Shimla Himachal Pradesh \\ *Corresponding Author \\ Dr Sapna Berry \\ VPO Bathri Tehsil Dalhousie, District Chamba Himachal Pradesh, India
}

\begin{abstract}
Background: Prematurity is still a major problem for health care services throughout the world. Respiratory distress syndrome (RDS) is the primary cause of morbidity and mortality in preterm newborns. Frequency of morbidity and mortality in infants treated with antenatal steroid is less than those delivered without this therapy. Many pregnant females deliver before term or 37 weeks; hence these may be advised antenatal corticosteroid therapy without creating significant maternal or fetal side effects.

Method: It was an observational study conducted in the department of obstetrics and gynecology IGMC Shimla for 1 year duration.

Results: The study sample of 244 was divided into two groups on the basis of exposure to antenatal corticosteroids. RDS was reported 57 cases (preterm neonates) in the study. It was seen in41 out of 165 cases of steroids uncovered group and 16 cases out of 79 of steroid covered group. Mortality among steroid uncovered group was seen in 71 preterm neonates out of 165 as compared to 10 neonatal deaths out of 79 in steroid covered group.

Conclusion: Mortality in the infants treated with antenatal corticosteroid is significantly less than the group of preterm newborns delivered without this therapy.
\end{abstract}

\section{Introduction}

Prematurity is still a major problem for health centers throughout the world. The incidence of preterm birth in the developed world is between 7-12\%. ${ }^{1}$ Respiratory distress syndrome (RDS), also known as hyaline membrane disease was the primary cause of morbidity and mortality in preterm newborns before 1980's. Maturation of fetal lungs is dependent on surfactant, which is a complex molecule. The prime factor for insufficient surfactant production and pulmonary immaturity is birth of a new-born before reaching the term. The incidence of RDS is $1-2 \% .^{2}$ Liggins and Howie first introduced steroid therapy in $1972 .{ }^{3}$ Since the introduction of steroid therapy in clinical practice, many randomized controlled studies have concluded the positive maturational effects of antenatal corticosteroids on fetal lungs, which decrease incidence and severity of hyaline membrane disease, reduce incidence of intra- 
ventricular hemorrhage, and overall reduce neonatal mortality. ${ }^{4}$ When prescribing the steroid therapy to the preterm pregnant women they may be informed that a single course of antenatal corticosteroid therapy is not associated with any significant side effects on the mother or foetus. ${ }^{5}$ However, multiple courses of antenatal corticosteroids may have adverse effects such as decreased fetal growth. Such treatment might also have long-term adverse eff ects; indeed, adverse neurological outcomes have been shown in follow-up studies of children given dexamethasone after birth. ${ }^{6}$

The incidence of RDS has an indirect relationship with the gestational age, meaning that it is high at early gestation and reduce with advancing gestation, from about $50 \%$ in babies born at 26-28 weeks to about $25 \%$ at $30-31$ weeks and $5 \%$ at 35 weeks. $^{7,8}$ It is a leading cause of mortality in preterm infants and accounts for $30 \%$ of all neonatal deaths. ${ }^{9}$

Dexamethasone and betamethasone are the corticosteroids recommended for antenatal therapy. ${ }^{10,11}$ The recommended regimen of steroid therapy according to National Institutes of Health Consensus is either of these: two doses of $12 \mathrm{mg}$ betamethasone given intramuscularly 24 hours apart or four doses of $6 \mathrm{mg}$ dexamethasone given intramuscularly 12 hours apart between 24 and 34 weeks of gestation in pregnancies at risk for preterm delivery. ${ }^{12,13}$

Significant benefit of steroid therapy can be seen 24 hours after the first dose and before 7 days. If the delivery occurs before 24 hours of initiation of regimen, there, even then significant reductions in neonatal mortality, RDS, and IVH is seen. So antenatal corticosteroids should be given in all cases of preterm birth except in a situation when delivery is imminent. ${ }^{1}$

\section{Methodology}

This was a one year observational study, conducted in the Department of obstetrics and gynecology IGMC Shimla Himachal Pradesh from $1^{\text {st }}$ August 2017 to $31^{\text {st }}$ July 2018.
Women who delivered at Gestation age $>24$ weeks to $<34$ weeks were included in the study. Data was collected from patients case sheet. Patients fell in either of these two groups depending on the time of delivery after complete course of steroid therapy. Group 1 "steroid covered" consisted of those patients who were administered $6 \mathrm{mg}$ dexamethasone 1/M four doses 12 hours apart and who delivered after 48 hrs but before 7 days of corticosteroid therapy. Group 2 "steroid uncovered" consisted of the patients who eitherdid not receive steroids or they were delivered without effectiveness of steroid therapy, i.e., before $48 \mathrm{hrs}$ or after 7 days. Neonates of these patients were followed from time of birth till first 7 days of life for development of any morbidity. If death of neonate occurred, then leading cause of death was obtained from Pediatric department.

\section{Exclusion Criteria}

- Pregnancy beyond 34 weeks.

- Any congenital malformations such as anencephaly, hydrocephalus or multiple congenital anomalies.

- Multiple pregnancies.

- Contraindications to steroids

\section{Statistical Analysis}

Data collected was transformed into MS excel sheet for further processing and analysis. Statistical analyses were performed using SPSS Parametric and non-parametric test of significance were used wherever applicable to find the association between different quantitative and qualitative variable of interest. P-value less than 0.05 were considered as statistically significant.

\section{Results}

Neonatal Morbidity: There were 244 live births before 34 weeks of gestation, out of which 165 were steroid uncovered and 79 belonged to steroid covered group. Out of 165 steroid uncovered cases neonatal morbidity was seen in $99(60 \%)$ while in case of steroid covered group, neonatal morbidity was seen $38(48.1 \%)$ cases out of 79 cases. RDS was most common morbidity in both groups. p- 
value was more than 0.05 which was not significant. Neonatal morbidity was not affected in babies below 34 weeks by beneficial effect of antenatal corticosteroids.

Table 1 Relationship between steroids and neonatal morbidity at $<34$ weeks

(Total live birth <34 weeks $=244$ )

\begin{tabular}{|l|c|c|}
\hline Morbidity & $\begin{array}{c}\text { Steroid uncovered } \\
\mathbf{n = 1 6 5}\end{array}$ & $\begin{array}{c}\text { Steroid covered } \\
\mathbf{n = 7 9}\end{array}$ \\
\hline RDS & 41 & 16 \\
\hline NNJ & 39 & 15 \\
\hline Sepsis & 10 & 4 \\
\hline IVH & 6 & 2 \\
\hline $\begin{array}{l}\text { Pulmonary } \\
\text { hemorrhage }\end{array}$ & 2 & 0 \\
\hline NEC & 1 & 1 \\
\hline Total & 99 & 38 \\
\hline Percentage & $60 \%$ & $48.1 \%$ \\
\hline
\end{tabular}

p-value $>0.05$

Neonatal Mortality: Out of 165 births who were steroid uncovered, neonatal deaths occurred in 71 (43\%) babies while out of 79 babies who received steroid, neonatal deaths occurred in only 10 $(12.6 \%)$ babies. p-value was $<0.05$ which was significant. Hence neonatal mortality was significantly reduced in cases where some time was gained for steroid coverage.

Table 2. Relationship between steroids and neonatal mortality at $<34$ weeks

(Total live birth $<34$ weeks $=244$ )

\begin{tabular}{|l|c|c|}
\hline Outcome & $\begin{array}{c}\text { Steroid uncovered } \\
\mathbf{n = 1 6 5}\end{array}$ & $\begin{array}{c}\text { Steroid covered } \\
\mathbf{n = 7 9}\end{array}$ \\
\hline Neonatal death & 71 & 10 \\
\hline $\begin{array}{l}\text { Neonatal } \\
\text { mortality }\end{array}$ & $43 \%$ & $12.6 \%$ \\
\hline
\end{tabular}

p-value $<0.05$

\section{Discussion}

A leading cause of respiratory distress in preterm newborns is hyaline membrane disease or RDS. The lungs of preterm newborns do not have sufficient pulmonary surfactants which normally forms a thin layer on alveolar surfaces. The main function of these surfactants is to increase the surface tension at the air-liquid interface in the alveoli and terminal airways and prevent alveoli to collapse. The etiology of RDS is surfactant deficiency which leads to atelectasis, impairment of gas exchange, and cause secondary lung damage. Surfactant deficiency is due to prematurity of lungs. The condition usually deteriorates for 2-4 days after birth with slow improvement thereafter. Severe respiratory distress syndrome can lead to death of new-born, although this is least likely to happen on the day 1 of life. Mortality usually occurs between days 27. ${ }^{1}$

Antenatal steroid treatment for women who are at risk of preterm delivery has evolved as the most effective treatment for the prevention of RDS, reducing early neonatal morbidity and mortality ${ }^{14}$ In a study by Singh $U$ et $\mathrm{al}^{15}$. morbidity and mortality was seen in $52.1 \%$ and $31 \%$ of the cases respectively, who did not receive steroids and in $37.5 \%$ and $29.2 \%$ of cases respectively who had received it. In our study neonatal mortality was significantly reduced, while in study by Singh U et $\mathrm{al}^{15}$. neonatal morbidity was significantly reduced by a course of steroids.

In the study of Shahzad $\mathrm{F}^{1}$ also mortality due to Respiratory distress syndrome among all preterm neonates was also significantly reduced in exposed group as compared to non-exposed group.

The mortality and major neonatal morbidity rates according to antenatal steroid therapy in the preterm SGA and non-SGA groups were significantly reduced in steroid covered group as compared to non covered group in the study by $\mathrm{S}$ Riskin-Mashiah el al. ${ }^{16}$

\section{Conclusion}

This study proves that respiratory distress syndrome is quite common among preterm newborns and antenatal dexamethasone significantly reduces its severity along with early neonatal mortality due to this disease in preterm newborns. This effect is more marked if newborn delivers after a period of effectiveness of antenatal corticosteroids. Hence it is proven that a single course of dexamethasone to a woman in preterm labour is highly cost-effective and gives promising results. Steroid therapy can lead to a drastic change in the profile of complications for preterm 
babies in developing countries, where preterm labour is a significant cause of neonatal mortality and where care for preterm babies is still not up to the mark, and the use of antenatal steroids remains a good opportunity in many hospitals.

\section{Acknowledgement}

Authors express their heartfelt gratitude to their colleagues of Obstetrics and Gynecology Department for collecting data and undoubtedly to the antenatal patients without whom this work could not have been possible.

\section{References}

1. Shahzad F, Umar N. Impact of antenatal corticosteroids on frequency and mortality due to respiratory distress syndrome in preterm neonates. J Ayub Med Coll Abbottabad.2016;28(4):698-701.

2. Grqic O, Matijevic R. Dilemmaas about the Antenatal use of corticosteroids for prevention of neonatal morbidity and mortality. Acta Med Croatica 2005;59(2):129-35.

3. Bonanno $\mathrm{C}$, Wapner RJ. Antenatal corticosteroid treatment: What's happened since Drs Liggins and Howie? Am J ObstetGynecol 2009;200(4):448-57.

4. Crowley P. Prophylactic corticosteroids for preterm delivery (Cochrane Review). Cochrane Libr 1999;1.

5. Antenatal corticosteroids to reduce to reduce neonatal morbidity and mortality. Green-top guideline No. 7, October 2010; p: 3,4.

6. Murphy KE, Hannah ME, Wilan AR et al. Multiple courses of antenatal corticosteroids for preterm birth : a randomised controlled trial. Lancet. 2008;372(9656):2143-51.

7. Bennet P. preterm labors. In: Edmonds DK, Dewhurst J, editors. Dewhurst's textbook of obstetrics \& gynaecology. 7th ed. Malden, Mass: Blackwell Pub; 2007. p.177-8.

8. Whitsett JA, Pryhuber GS, Rice WR, Warner BB, Wert SE. Acute respiratory disorders. In: Avery GB, Fletcher MA, MacDonald MG, editors. Neonatology: Pathophysiology and Management of the Newborn. 4th ed. Philadelphia, PA: JB Lippincott Company; 1994. p.429-52.

9. Shirazi H, Riaz S, Mahmood RA. Morbidity and Mortality Pattern of Newly Born Babies in a Teaching Hospital. J Rawal Med Coll 2015;19(3):204-8.

10. Klinger G, Koren G. Controversies in antenatal corticosteroid treatment. Can Fam Physician 2000;46:1571-3.

11. Effect of corticosteroids for foetal maturation on perinatal outcomes. NIH Consens Statement 1994;12(2):1-24.

12. Wang K, Chen CY, Chen CP. Effects of Antenatal Corticosteroids in Preterm Delivery. Taiwan J Obstet Gynaecol 2004;43(4):193-8.

13. Mwansa-Kambafwile J, Cousens S, Hansen T, Lawn JE. Antenatal steroids in preterm labour for the prevention of neonatal deaths due to complications of preterm birth. Int $\mathbf{J}$ Epidemiol 2010;39(Suppl 1):i122-33.

14. Roberts D, Dalziel S. Antenatal corticosteroids for accelerating foetal lung maturation for women at risk of preterm birth. Cochrane Database Syst Rev 2006;3:CD004454.

15. Singh U, Singh N, Seth S. A prospective analysis of etiology and outcome of preterm labor. J ObstetGynecol India 2007;57(1):4852.

16. Riskin-Mashiah, S, Riskin A, Bader D, Kugelman A,Boyko V, Lerner-Geva L et al. Antenatal corticosteroid treatment in singleton, small-for-gestational-age infants born at 24- 31 weeks' gestation: a population-based study. BJOG 2016;123: 1779-86. 